\title{
Enhanced oxidative stress with a gradient between plasma and muscle interstitial fluid in patients with end stage renal failure on hemodialysis
}

\author{
Ioannis Karamouzis, ${ }^{1}$ Dimitrios Grekas, ${ }^{2}$ Michael Karamouzis, ${ }^{1}$ Athanasios Triantos, ${ }^{1}$ \\ Svetla Vasileva-Staikova, ${ }^{3}$ Dimitrios Kovachev, ${ }^{4}$ Afroditi Dimitriadou ${ }^{1}$
}

${ }^{1}$ Biochemistry Laboratory, School of Medicine, University of Thessaloniki, ${ }^{2}$ First Medical Department, School of Medicine, AHEPA Hospital, Thessaloniki, Greece, ${ }^{3}$ Clinic of Nephrology and Hemodialysis, Medical University of Varna, ${ }^{4}$ Biology Laboratory, Medical School, University of Varna, Bulgaria

\begin{abstract}
OBJECTIVE: The concentration of 8-iso-prostaglandin-F $F_{2 \alpha}\left(8-\right.$-iso- $\left._{\text {PGF }} \alpha\right)$ in biological fluids has been considered as the most reliable biochemical index of the lipid peroxidation and oxidative stress in patients with several pathological conditions including end stage renal failure. However, there is no reference regarding the influence of Hemodialysis (HD) on the values of 8-iso-PGF $F_{2 \alpha}$ in the muscle Interstitial Fluid (IF) of patients with end stage renal failure. The

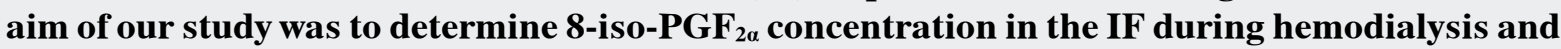
the gradient between plasma and IF in patients with end stage renal failure. DESIGN: In this study, two microdialysis probes were inserted into the vastus lateralis muscle of the right leg of six male patients with end stage renal failure who were on hemodialysis, and in six healthy males (controls). The samples of IF (12 dialysate fluids) were collected after an equilibration of 30 min: a) during the $1^{\text {st }}$ hour preceding hemodialysis (group $C_{R F}$ ), b) during the $1^{\text {st }}, 2^{\text {nd }}, 3^{\text {rd }}$ and $4^{\text {th }}$ hour while on hemodialysis (groups $C R F_{1}, C R F_{2}, C R F_{3}$ and $C R F_{4}$ ) and c) during the $1^{\text {st }}$ hour following hemodialysis (group $\mathrm{CRF}_{5}$ ). At the end of the above periods and simultaneously, blood samples were drawn from the arteriovenous fistula. In the controls, the IF samples (twelve dialysate fluids) were collected during a period of one hour and the blood samples at the end of this period. The levels of 8 -iso-PGF - $_{2 a}$ were measured with an enzyme-immunoassay method. Statistical evaluation was carried out with the statistical program NCSS 2000 and the ANOVA test. RESULTS: Plasma and IF levels of 8-iso-PGF $2 \alpha$ in the patients were significantly higher than in controls at base line. During hemodialysis, the 8-iso-PGF PG $_{2 \alpha}$ rose progressively both in plasma and IF but remained higher in plasma than in IF. CONCLUSIONS: Lipid peroxidation is higher in patients on hemodialysis than in controls but it is lower in the IF compared to plasma. The mechanism for this gradient is speculative.
\end{abstract}

Key words: Hemodialysis, Lipid peroxidation, Microdialysis, Oxidative stress 8-iso-PGF ${ }_{2 \alpha}$, Renal failure, $15-\mathrm{F}_{2 t}$-isoprostane 


\section{INTRODUCTION}

8-iso-prostaglandin- $\mathrm{F}_{2 \alpha}\left(\right.$ 8-iso- $\left.\mathrm{PGF}_{2 \alpha}\right)$ is a characteristic $\mathrm{F}_{2}$-isoprostane, which is produced non-enzymatically in human cells via a free radical-catalysed lipid peroxidation mechanism of arachidonic acid, independent of the cyclooxygenase pathway. 8-isoprostaglandin- $\mathrm{F}_{2 \alpha}$ or 8 -iso- $\mathrm{PGF}_{2 \alpha}$ is the old nomenclature, while the new one proposed by Taber is 15 $\mathrm{F}_{2 \mathrm{t}}$-isoprostane or $15-\mathrm{F}_{2 \mathrm{t}}$-IsoP. In this paper, however, the old nomenclature will be used.

There are 64 diastereoisomers isoprostanes but 8iso-PGF ${ }_{2 \alpha}$ is the most biologically active. It is present in humans in two distinct forms: esterified in LDL phospholipids and as free acid. The ratio of these two forms is approximately 2:1. 8-iso- $\mathrm{PGF}_{2 \alpha}$ has been shown to be a potent vasoconstrictor and a potent mediator of hepatorenal syndrome and atherosclerosis. It has been also postulated to act as a pathophysiological mediator, able to modify the fluidity and integrity of cell membranes. ${ }^{1-4}$

The plasma levels of 8-iso-PGF ${ }_{2 \alpha}$ have been considered the most reliable biochemical index of lipid peroxidation and oxidative stress level in patients with several pathological conditions, including end stage renal failure. ${ }^{5-12}$ However, there is no reference in the literature regarding the effect of hemodialysis on the production and accumulation of 8 -iso- $\mathrm{PGF}_{2 \alpha}$ in the Interstitial muscle's Fluid (IF) of hemodialysed patients, nor are there data on the simultaneous changes of the levels of 8 -iso- $\mathrm{PGF}_{2 \alpha}$ in the plasma and IF during hemodialysis.

During the last ten years, a microdialysis technique has been applied in different tissues such as the brain, the bones, the connective tissue, the adipose tissue and the skeletal muscles. ${ }^{13-16}$ This technique is based on the principle of diffusion of substances with molecular weight below 20,000 Da (like 8-iso-PGF ${ }_{2 \alpha}$ ) through a semi-permeable membrane (microdialysis probe). The dialysate fluid contains no enzymes or proteins, hence this technique allows the isolation, purification and quantitative measurements of these compounds in the interstitial space of various tissues. ${ }^{17,18}$

The eicosanoid hormones (derivatives of arachidonic acid, prostaglandins, prostacyclins, thromboxanes and $\mathrm{F}_{2}$-isoprostanes) have low molecular weight
$(<5.000 \mathrm{Da})$ and can thus be isolated from the IF of the muscle with the use of this microdialysis technique. After the isolation of these locally produced hormones, it is easy to measure their concentration in the IF via a sensitive immunoassay method such as Radioimmunoassay (RIA) or Enzyme Immunoassay (EIA). ${ }^{17-19}$

In a previous study using the microdialysis technique, we demonstrated the existence of 8 -iso- $\mathrm{PGF}_{2 \alpha}$ in the IF of the skeletal muscles of healthy individuals. $^{18}$

In the present study, we determined the values of 8 -iso-PGF $\mathrm{PG}_{2 \alpha}$ as an index of lipid peroxidation in plasma and IF thoughout hemodialysis, also looking for a possible gradient between plasma and IF in patients with end stage renal failure.

\section{SUBJECTS AND METHODOLOGY}

The study included two groups: a) six stabilized male patients with end stage renal failure who were on hemodialysis (non smokers, aged 49 to 55 years) and b) six healthy individuals, non smokers, of the same age range, who served as controls (Table 1). All patients had well-functioning forearm arteriovenous fistula. The respective diagnoses were diabetic nephropathy, nephrosclerosis and polycystic kidney disease; their time on dialysis ranged from 15 to 35 months (Table 1). The filters used were fresinius polysulfone capillary dialysis with $1.6 \mathrm{~m}^{2}$ effective surface area.

Two microdialysis probes (length $30 \mathrm{~mm}$, inner diameter $0.52 \mathrm{~mm}$, permeable by substances with a molecular mass less than 20,000 Da) were inserted with a CMA 60 microdialysis catheter (CMA medical, Stockholm, Sweden) into the vastus lateralis of the quadriceps femoris muscle group of the right leg. Before the insertion of the catheters, local anesthesia was achieved with $1 \mathrm{ml}$ of lidocoine (10 $\mathrm{mg} / \mathrm{ml}$ ) administered above the muscle facia. After insertion, the microdialysis probes were attached to a perfusion pump (CMA model 102) and perfused at a rate of $0.3 \mu \mathrm{l} / \mathrm{min}$ with ringer acetate solution. The samples (12 dialysate fluids) were collected after an equilibration of $30 \mathrm{~min}$ : a) during one hour preceding hemodialysis (group $\mathrm{CRF}_{0}$ ), b) during the $1^{\text {st }}, 2^{\text {nd }}, 3^{\text {rd }}$ 
Table 1. Descriptive data of the patients (age, gender, cause of hemodialysis (HD), time on HD, smoking).

\begin{tabular}{cccccc}
\hline Patients & $\begin{array}{c}\text { Age } \\
\text { (years) }\end{array}$ & Gender & Cause of HD & $\begin{array}{c}\text { Time on HD } \\
\text { (months) }\end{array}$ & Smoking \\
\hline 1. & 49 & 0 & Diabetic nephropathy & 19 & NO \\
2. & 51 & 0 & nephrosclerosis & 15 & NO \\
3. & 55 & 0 & Diabetic nephropathy & 28 & NO \\
4. & 53 & 0 & nephrosclerosis & 22 & NO \\
5. & 52 & 0 & Polycystic kidney disease & 25 & NO \\
6. & 54 & 0 & Diabetic nephropathy & 35 & NO \\
mean \pm SD & $52.33 \pm 2.16$ & & & $24.00 \pm 4.62$ & \\
\hline
\end{tabular}

and $4^{\text {th }}$ hour while on hemodialysis (groups $\mathrm{CRF}_{1}$, $\mathrm{CRF}_{2}, \mathrm{CRF}_{3}$ and $\mathrm{CRF}_{4}$ ) and c) during the $1^{\text {st }}$ hour following hemodialysis (group $\mathrm{CRF}_{5}$ ).

As the volume in the sampling system from the distal end of the catheter to the microvials was 2.9 $\mu \mathrm{l}$, the time required for the microdialysate to reach the microvials from the interstitial tissue was approximately $10 \mathrm{~min}$. This sampling delay was taken into account when the dialysate fluids were collected. In order to eliminate the effect of local inflammation and tissue disturbances, the catheters were inserted 30 min before the collection of the dialysate fluid began (before hemodialysis). In order to avoid bleeding complications due to heparinization, the catheter was inserted 90 min before the beginning of hemodialysis.

A blood sample was drawn at the end of each IF sampling from the arteriovenous fistula (in sealed ice-cold microcentrifuge tubes) using EDTA ( $3 \mathrm{mg} /$ $\mathrm{ml})$ as anticoagulant and indomethacin $(10 \mu \mathrm{g} / \mathrm{ml})$ as prostaglandin synthetase inhibitor. In the controls, the samples (12 dialysate fluids) were collected during a period of one hour and the blood samples at the end of this period. After the centrifugation (at $4^{\circ} \mathrm{C}$ ) of the blood samples at about $1500 \mathrm{~g}$, plasma samples and dialysate fluid samples were stored at $-70^{\circ} \mathrm{C}$ until determination of 8 -iso-PGF PG $_{2 \alpha}$ (about a month). In order to measure the levels of 8 -iso-PGF ${ }_{2 \alpha}$ in the interstitial fluid of the vastus lateralis muscle and in the plasma samples after purification in a C-18 SPE cartridge (Catalog No. 400020), we employed a sensitive and reliable enzymo-immunoassay method using kits of Cayman chemical company www.caymanchem. com (catalogue No 516351). The above method can measure the free (non-esterified) or the total (free and esterified) 8 -iso-PGF $2 \alpha$. In this study the free form was measured. ${ }^{18}$

The performance characteristics of this immunoassay method were as follows:

a) Precision: The intra and inter assay coefficient of variation $(\mathrm{CV} \%)$ was $5.1 \%$ and $7.3 \%$, respectively.

b) Sensitivity: The sensitivity of the assay was $5 \mathrm{pg} /$ $\mathrm{ml}$.

c) Specificity: The 8-iso- $\mathrm{PGF}_{2 \alpha}$ antiserum used in this assay, binds to: 8 -iso- $\mathrm{PGF}_{2 \alpha} 100.00 \%, 8$-iso- $\mathrm{PGF}_{3 \alpha}$ $20.55 \%, 2.3$-dinor-8-iso- $\mathrm{PGF}_{2 \alpha}=4.0 \%$ 8-iso- $\mathrm{PGE}_{2}$ $1.84 \%$, 2,3-dinor-8-iso-PGF PG $_{1 \alpha} 1.7 \%$, 8-iso-PGE $1.56 \%, \mathrm{PGF}_{1 \alpha} 0.71 \%, \mathrm{PGF}_{3 \alpha} 0.66 \%, \mathrm{PGE}_{1} 0.39 \%$, $\mathrm{PGD}_{2} 0.16 \%$, 6-keto-PGF $\mathrm{PF}_{1 \alpha} 0.14 \%, \mathrm{PGF}_{2 \alpha} 0.14 \%$, 2,3 dinor-6-ketoPGF $\mathrm{P}_{\alpha} 0.09 \%$, 8-iso-PGF $1 \beta 0.08 \%$, $\mathrm{TXB}_{2} 0.08 \%, 11-(\mathrm{OH})_{2}-\mathrm{TXB}_{2} 0.07 \%$ and other prostaglandine metabolites $<0.1 \%$.

d) Recovery: The average $\%$ recovery of this assay was $109 \%$ (range $98-119 \%$ ).

e) The microdialysis probe recovery was evaluated at almost $100 \%$ in experimental conditions because the perfusion pump perfused at an equally very slow rate of $0.3 \mu \mathrm{l} / \mathrm{min}$ before, during and after hemodialysis. The low flow rate of $0.3 \mu \mathrm{l} / \mathrm{min}$ was used to allow almost complete equilibration with the interstitial fluid and to avoid draining of the extracellular space. This almost $100 \%$ recovery with a flow rate of $0.3 \mu \mathrm{l} / \mathrm{min}$ was determined in our previous study. ${ }^{18}$

The statistical evaluation was carried out with 
the statistical program NCSS 2000 and the ANOVA test and, specifically, with the randomized complete block design where blocks were the subjects and treatment the repeated measures. Bonferroni correction was used to adjust for multiple comparisons between groups.

Informed written consent was obtained from the subjects included in this study and the study was approved by the Ethics Committee of the School of Medicine, Aristotle University of Thessaloniki, Greece.

\section{RESULTS}

The levels of 8-iso-PGF $2 \alpha$ in the plasma and IF of the patients as well as their statistical evaluation are shown in Tables 2 and 3 and in Figure 1.

As shown in Table 2 and in Figure 1, the plasma levels of 8-iso-PGF ${ }_{2 \alpha}$ in the patients prior to hemodialysis initiation were higher $(330.8 \pm 42.2 \mathrm{pg} / \mathrm{ml})$ than in controls $(25.6 \pm 5.1 \mathrm{pg} / \mathrm{ml})(\mathrm{p}<0.001)$. During hemodialysis, the plasma levels of 8 -iso-PGF ${ }_{2 \alpha}$ in the patients gradually increased and reached a maximum value at the end of the third hour of the hemodialysis, was almost stabilized at the end of the fourth hour and decreased significantly at the first hour following hemodialysis. Specifically, the plasma levels of 8-iso$\mathrm{PGF}_{2 \alpha}$ were as follows: a) one hour after hemodialysis initiation, they were higher $(533.6 \pm 55.2 \mathrm{pg} / \mathrm{ml})$ than those prior to hemodialysis initiation $(p=0.006), b)$ at the second hour of hemodialysis, the values were $584.2 \pm 57.8 \mathrm{pg} / \mathrm{ml}$, significantly different than during the first hour $(\mathrm{p}=0.049), \mathrm{c})$ at the third hour of hemodialysis, they reached the level of $664.2 \pm 73.1 \mathrm{pg} / \mathrm{ml}$ and were higher than the second hour of hemodialysis $(p=0.039)$. At the fourth hour on hemodialysis, the values were stabilized at $648.0 \pm 60.3 \mathrm{pg} / \mathrm{ml}$ without a significant difference from the levels of the third hour of hemodialysis $(p=0.386)$. At the first hour after hemodialysis, the values decreased (549.0 \pm 64.4 $\mathrm{pg} / \mathrm{ml}$ ) and were lower than the levels at the fourth hour of hemodialysis $(p=0.033)$.

As shown in Table 3 and in Figure 1, the IF levels of 8 -iso-PGF $\mathrm{P}_{2 \alpha}$ of hemodialysed patients before the beginning of hemodialysis were significantly higher $(150.1 \pm 22.2 \mathrm{pg} / \mathrm{ml})$ than the levels in the controls $(24.1 \pm 4.1 \mathrm{pg} / \mathrm{ml})$ with a $\mathrm{p}$ value $<0.001$. During hemodialysis, the IF levels of 8-iso- $\mathrm{PGF}_{2 \alpha}$ gradually increased and reached a maximum value at the end of the third hour of the hemodialysis, were almost stabilized at the end of the fourth hour and decreased significantly at one hour following hemodialysis. Specifically, the IF levels of 8 -iso-PGF $\mathrm{PG}_{2 \alpha}$ were as follows: a) at one hour on hemodialysis, the values were higher $(271.9 \pm 31.4 \mathrm{pg} / \mathrm{ml})$ than those before the start of hemodialysis $(\mathrm{p}=0.006), \mathrm{b})$ at the second hour on hemodialysis, they rose further and were higher $(299.7 \pm 32.6 \mathrm{pg} / \mathrm{ml})$ than the levels during

Table 2. Plasma 8-iso- $\mathrm{PGF}_{2 \alpha}($ mean $\pm \mathrm{SD})$ in Controls $(\mathrm{C})$ and in patients prior to $\left(\mathrm{CRF}_{0}\right)$, and during hemodialysis $\left(\mathrm{CRF}_{1}, \mathrm{CRF}_{2}, \mathrm{CRF}_{3}\right.$, $\mathrm{CRF}_{4}$ and $\mathrm{CRF}_{5}$ ) and their statistical evaluation.

\begin{tabular}{|c|c|c|c|c|c|c|c|}
\hline & \multicolumn{7}{|c|}{ 8-iso-PGF ${ }_{2 \alpha} \mathrm{pg} / \mathrm{ml}$} \\
\hline & $\mathrm{C}$ & $\mathbf{C R F}_{0}$ & $\mathrm{CRF}_{1}$ & $\mathrm{CRF}_{2}$ & $\mathrm{CRF}_{3}$ & $\mathrm{CRF}_{4}$ & $\mathrm{CRF}_{5}$ \\
\hline & 25.6 & 330.4 & 533.6 & 584.2 & 664.2 & 648.0 & 549.0 \\
\hline & \pm 5.1 & \pm 42.2 & \pm 55.2 & \pm 57.8 & \pm 73.1 & \pm 60.3 & \pm 64.4 \\
\hline 1. & & $\mathrm{p}<0.001$ & $\mathrm{p}<0.001$ & $\mathrm{p}<0.001$ & $\mathrm{p}<0.001$ & $\mathrm{p}<0.001$ & $\mathrm{p}<0.001$ \\
\hline 2. & & & $\mathrm{p}=0.006$ & $\mathrm{p}=0.004$ & $\mathrm{p}=0.001$ & $\mathrm{p}=0.003$ & $\mathrm{p}=0.005$ \\
\hline 3. & & & & $\mathrm{p}=0.049$ & $\mathrm{p}=0.015$ & $\mathrm{p}=0.025$ & $\mathrm{p}=0.982$ \\
\hline 4. & & & & & $\mathrm{p}=0.039$ & $\mathrm{p}=0.053$ & $p=0.508$ \\
\hline 5. & & & & & & $\mathrm{p}=0.386$ & $\mathrm{p}=0.023$ \\
\hline 6. & & & & & & & $\mathrm{p}=0.033$ \\
\hline
\end{tabular}

Comparison of the mean values of 8 -iso- $\mathrm{PGF}_{2 \alpha}$ of the groups:

1. $\mathrm{C}$ versus $\mathrm{CRF}_{0}, \mathrm{CRF}_{1}, \mathrm{CRF}_{2}, \mathrm{CRF}_{3}, \mathrm{CRF}_{4}$ and $\mathrm{CRF}_{5}$

2. $\mathrm{CRF}_{0}$ versus $\mathrm{CRF}_{1}, \mathrm{CRF}_{2}, \mathrm{CRF}_{3}, \mathrm{CRF}_{4}$ and $\mathrm{CRF}_{5}$

3. $\mathrm{CRF}_{1}$ versus $\mathrm{CRF}_{2}, \mathrm{CRF}_{3}, \mathrm{CRF}_{4}$ and $\mathrm{CRF}_{5}$

Designation of $\mathrm{CRF}_{1}$ to $\mathrm{CRF}_{5}$ are given in the section on subjects and methods.
4. $\mathrm{CRF}_{2}$ versus $\mathrm{CRF}_{3}, \mathrm{CRF}_{4}$ and $\mathrm{CRF}_{5}$

5. $\mathrm{CRF}_{3}$ versus $\mathrm{CRF}_{4}$ and $\mathrm{CRF}_{5}$

6. $\mathrm{CRF}_{4}$ versus $\mathrm{CRF}_{5}$ 


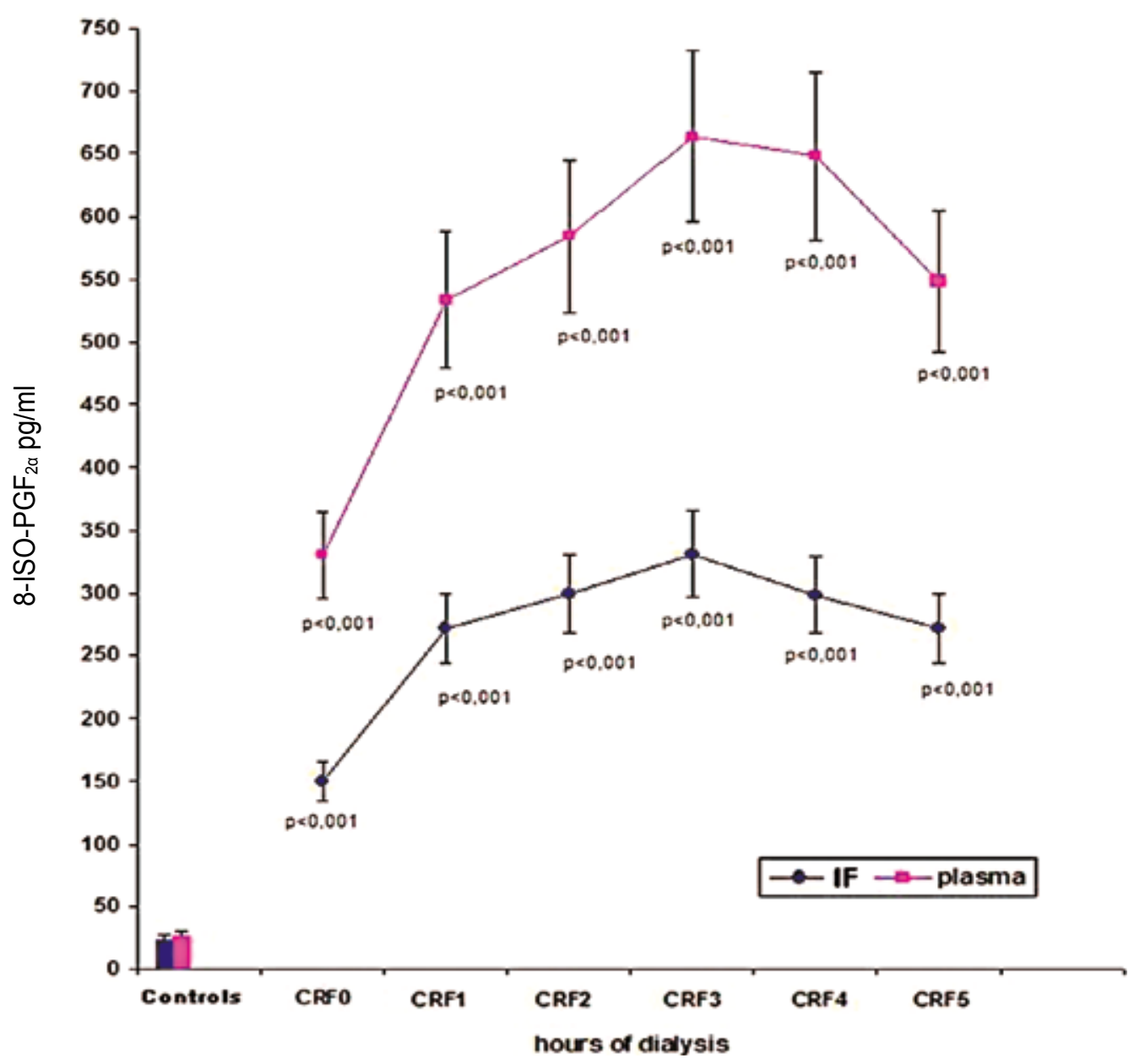

Figure 1. Values of 8-iso-PGF ${ }_{2 \alpha}$ (mean $\left.\pm \mathrm{SD}\right)$ in the plasma $(\square)$ and in the Interstitial Fluid (IF) $(\bullet)$ of the muscles in patients with chronic renal failure are higher than in controls. The values of 8 -iso- $-\mathrm{PGF}_{2 a}($ mean $\pm \mathrm{SD})$ in plasma and IF rise during hemodialysis with a significant gradient between plasma and IF prior to $\left(\mathrm{CRF}_{0}\right)$ and during hemodialysis $\left(\mathrm{CRF}_{1}-\mathrm{CRF}_{5}\right)$. Controls: Columns $\bullet \mathrm{IF}$, - plasma.

Table 3. Interstitial fluid 8-iso- $\mathrm{PGF}_{2 \alpha}$ (mean $\left.\pm \mathrm{SD}\right)$ in controls $(\mathrm{C})$ and in patients prior to $\left(\mathrm{CRF}_{0}\right)$, and during hemodialysis $\left(\mathrm{CRF}_{1}, \mathrm{CRF}_{2}\right.$, $\mathrm{CRF}_{3}, \mathrm{CRF}_{4}$ and $\mathrm{CRF}_{5}$ ) and their statistical evaluation.

\begin{tabular}{|c|c|c|c|c|c|c|c|}
\hline & \multicolumn{7}{|c|}{ 8-iso-PGF ${ }_{2 a} \mathrm{pg} / \mathrm{ml}$} \\
\hline & $\mathrm{C}$ & $\mathrm{CRF}_{0}$ & $\mathrm{CRF}_{1}$ & $\mathrm{CRF}_{2}$ & $\mathrm{CRF}_{3}$ & $\mathrm{CRF}_{4}$ & $\mathrm{CRF}_{5}$ \\
\hline & 21.1 & 150.1 & 271.9 & 299.7 & 330.8 & 298.9 & 272.0 \\
\hline & \pm 4.1 & \pm 22.2 & \pm 31.4 & \pm 32.6 & \pm 33.6 & \pm 34.9 & \pm 31.8 \\
\hline 1. & & $\mathrm{p}<0.001$ & $\mathrm{p}<0.001$ & $\mathrm{p}<0.001$ & $\mathrm{p}<0.001$ & $\mathrm{p}<0.001$ & $\mathrm{p}<0.001$ \\
\hline 2. & & & $\mathrm{p}=0.006$ & $\mathrm{p}=0.003$ & $\mathrm{p}=0.001$ & $\mathrm{p}=0.004$ & $\mathrm{p}=0.005$ \\
\hline 3. & & & & $\mathrm{p}=0.048$ & $\mathrm{p}=0.022$ & $\mathrm{p}=0.049$ & $p=0.734$ \\
\hline 4. & & & & & $\mathrm{p}=0.035$ & $\mathrm{p}=0.999$ & $p=0.048$ \\
\hline 5. & & & & & & $\mathrm{p}=0.238$ & $p=0.024$ \\
\hline 6. & & & & & & & $p=0.049$ \\
\hline
\end{tabular}

Comparison of the mean values of 8-iso- $\mathrm{PGF}_{2 \alpha}$ of the groups:

1. $\mathrm{C}$ versus $\mathrm{CRF}_{0}, \mathrm{CRF}_{1}, \mathrm{CRF}_{2}, \mathrm{CRF}_{3}, \mathrm{CRF}_{4}$ and $\mathrm{CRF}_{5}$

4. $\mathrm{CRF}_{2}$ versus $\mathrm{CRF}_{3}, \mathrm{CRF}_{4}$ and $\mathrm{CRF}_{5}$

2. $\mathrm{CRF}_{0}$ versus $\mathrm{CRF}_{1}, \mathrm{CRF}_{2}, \mathrm{CRF}_{3}, \mathrm{CRF}_{4}$ and $\mathrm{CRF}_{5}$

3. $\mathrm{CRF}_{1}$ versus $\mathrm{CRF}_{2}, \mathrm{CRF}_{3}, \mathrm{CRF}_{4}$ and $\mathrm{CRF}_{5}$

5. $\mathrm{CRF}_{3}$ versus $\mathrm{CRF}_{4}$ and $\mathrm{CRF}_{5}$

Designation of $\mathrm{CRF}_{1}$ to $\mathrm{CRF}_{5}$ are given in the section on subjects and methods. 
the first hour $(\mathrm{p}=0.048), \mathrm{c})$ at the third hour on hemodialysis, they reached their maximum levels $(330.8 \pm 33.6 \mathrm{pg} / \mathrm{ml})$ and were higher than the levels during the second hour of hemodialysis $(\mathrm{p}=0.035), \mathrm{d})$ at the fourth hour on hemodialysis, the values were stabilized at $298.9 \pm 34.9 \mathrm{pg} / \mathrm{ml}$ without a statistically significant difference from the levels of the third hour $(p=0.999), e)$ at one hour after hemodialysis, the values decreased $(272.0 \pm 31.8 \mathrm{pg} / \mathrm{ml})$ significantly and were lower compared to those at the fourth hour of hemodialysis $(\mathrm{p}=0.049)$.

\section{DISCUSSION}

The concentration of 8-iso-prostaglandin- $\mathrm{F}_{2 \alpha}$ (8iso-PGF ${ }_{2 \alpha}$ ) in biological fluids has been considered as the most reliable biochemical index of lipid peroxidation in patients with several pathological conditions including end stage renal failure.

Using an enzyme-immunoassay method which has good precision, sensitivity and specificity, ${ }^{18,22,25,26}$ we showed that the plasma and IF levels of 8-iso- $\mathrm{PGF}_{2 \alpha}$ of patients with end stage renal failure prior to hemodialysis initiation were significantly higher than the base line levels in controls. During hemodialysis, the plasma and IF levels of 8 -iso- $\mathrm{PGF}_{2 \alpha}$ gradually increased to reach a peak at the third hour.

A gradient between plasma and IF with regard to the 8 -iso-PGF ${ }_{2 \alpha}$ values was observed throughout the study period, the values in plasma being higher than in the IF space. The increased plasma levels of 8-iso$\mathrm{PGF}_{2 \alpha}$ found in this study in patients with end stage renal failure before, during and after hemodialysis are in agreement with the findings of certain researchers who used either the classical gas Chromatography/ Mass Spectrometry Method (GC/MS) ${ }^{10,19-21}$ or the new enzymo-immunoassay method that we used ${ }^{18,22}$ for 8-iso-PGF2 $\alpha$ determination. However, Ferraro et $\mathrm{al}^{23}$ and Kim et $\mathrm{al}^{24}$ found no difference in the 8 -iso-PGF ${ }_{2 \alpha}$ plasma levels between normal subjects and hemodialysis patients before the hemodialysis session. Nevertheless, Kim et al found much higher values (6-fold) in patients after hemodialysis compared to normal subjects. We should note that the values found by Kim et al in normal subjects were much higher $(960 \mathrm{pg} / \mathrm{ml})$ than the respective values in healthy individuals reported by other researchers $(\sim 150 \mathrm{pg} / \mathrm{ml})$ and also found in our study $(25.6 \pm 5.1$ $\mathrm{pg} / \mathrm{ml})$. These differences may be attributed to environmental and dietery factors ${ }^{25-30}$ or possibly to the fact that the normal subjects studied by Kim et al were active or passive smokers. It is known that smokers have 7-fold higher levels of 8-iso-PGF $\mathrm{PG}_{2 \alpha}$ in their plasma than non-smokers. ${ }^{19,28}$ Similarly, Ferraro et $\mathrm{a}^{23}$ found no difference in 8-iso-PGF ${ }_{2 \alpha}$ plasma levels $(246 \mathrm{pg} / \mathrm{ml})$ between patients before hemodialysis and normal subjects $(252 \mathrm{pg} / \mathrm{ml})$. This difference may also be due to inappropriate selection of their normal subjects. It should be mentioned that small differences in the values obtained are possibly due to different dietetic and environmental exposure of the patients ${ }^{26-31}$ in the various studies.

In our study, the plasma levels of 8-iso-PGF ${ }_{2 \alpha}$ were significantly higher than the respective levels in the IF prior to and at all phases of the hemodialysis $(\mathrm{p}<0.001)$. The plasma levels of 8 -iso-PGF ${ }_{2 \alpha}$ before the hemodialysis initiation were 16-fold higher than those in controls, while in the IF they were 10-fold higher. IF levels of 8-iso- $\mathrm{PGF}_{2 \alpha}$ prior to hemodialysis initiation found in this study confirmed the findings of a previous study of ours, ${ }^{32}$ whereas the gradual increase of 8 -iso-PGF - $_{2 \alpha}$ in the IF during hemodialysis, disclosed in the present study, has not previously been reported. It must be underlined that, compared to plasma levels, the IF levels of 8-iso-PGF ${ }_{2 a}$ more accurately reflect the status of oxidative stress in the organism, since enzymes in plasma can break the 8-iso-PGF ${ }_{2 a}$ molecule down into its derivatives, a reaction which is not expected in the IF. ${ }^{17,18}$

The higher levels of 8-iso-PGF ${ }_{2 \mathrm{a}}$ in plasma compared to those in the IF could be attributed to: a) an increased oxitative stress derived from a direct contact of blood elements with the surface of the hemodialysis filter connections, and b) to the much higher peroxidation of the arachidionic acid in the plasma by the free radicals compared to the oxidation of the arachidionic acid of the phospholipids of tissue cellular membranes. ${ }^{33,34}$

The high 8-iso-PGF ${ }_{2 \mathrm{a}}$ levels in the biological fluids in patients with Chronic Renal Failure (CRF) might be attributed to the increased oxidative stress and the increased lipid peroxidation in these patients, especially those in the last stages of the disease. The 
increased oxidative stress and the increased lipid peroxidation of these patients must be attributed to the increased production of free radicals (oxygen and nitrogen mainly) and to the loss of the antioxidants during hemodialysis. ${ }^{11,12,31,32}$

The increased oxidative stress and the increased lipid peroxidation of the patients with $\mathrm{CRF}$ on hemodialysis are probably due to: a) the uremic environment which causes the increased production of free radicals from polymorphonuclear leucocytes, ${ }^{35,36} \mathrm{~b}$ ) the loss of hydrosoluble antioxidizing-reducing substances of low molecular weight during hemodialysis, ${ }^{37,38} \mathrm{c}$ ) the bio-incompatibility of filter membranes of the artificial kidney that are used during hemodialysis, ${ }^{33,34}$ d) the contamination of the hematocatharsis solution by endotoxins and pyrogens, which activate the macrophages and produce larger quantities of free radicals. ${ }^{33,34}$ The contact of the blood with the plastic tubes during hemodialysis activates the polymorphonuclear leucocytes, resulting in an even higher production of free radicals. The afore-mentioned interpretations are reinforced by the fact that in the present study, 8-iso- $\mathrm{PGF}_{2 \alpha}$ levels were more than double in the blood plasma of the patients during hemodialysis than in the muscle IF. ${ }^{33,34}$

Moreover, all patients undergoing hemodialysis are exposed to various environmental as well as nutritional factors, which exert a significant effect, though at a different level from that experienced by patients suffering from CRF but not on hemodialysis. ${ }^{26-30}$ Thus, recent literature data indicate that, in general, the oxidative stress and the resultant lipid peroxidation are increased further by: a) smoking (active or passive), ${ }^{28}$ and b) exposure to increased environmental $\left(\mathrm{O}_{3}\right)^{25}$ and Ultraviolet radiation (UV). ${ }^{27}$ On the other hand, individuals who consume large quantities of vitamin $\mathrm{C}$ and/or vitamin $\mathrm{E}$, drink large quantities of black or green tea or consume olive oil have lower oxidative stress and lower lipid peroxidation. ${ }^{29-31}$

In summary, in patients with end stage renal failure: a) lipid peroxidation is increased, as compared to that of normal individuals, b) lipid peroxidation rises further and in parallel in plasma and in IF during hemodialysis, c) lipid peroxidation in the IF space is lower than in the plasma prior to and during hemodialysis. The mechanism for this gradient remains speculative.

\section{REFERENCES}

1. Chiabrando C, Rivalta C, Bagnati R, et al, 2002 Identification of metabolites from type III F2-isoprostane diastereoisomers by masspectrometry. J Lipid Research 43: 495-509.

2. Roberts LJ, Morrow JD, 2000 Measurement of F2-isoprostanes as index of oxidative stress in vivo. Free Radical Biol Med 28: 505-513.

3. Lawson JA, Rokain J, Fitzgerald GA, 1999 Isoprostane: formation, analysis and use as indices of lipid peroxidation in vivo. J Biol Chem 274: 24441-24444.

4. Morrow JD, Hill KE, Burk RF, Nammour TM, Badr KF, Roberts LJ 2nd, 1990 A series of prostaglandin F2-like compounds are produced in vivo in human by a non-cyclooxygenase, free radical-catalyzed mechanism. Proc Natl Acad Sci USA 87: 9383-9387.

5. Morrow JD, Minton TA, Roberts LJ 2nd, 1992 The F2isoprostane, 8-epi-prostaglandin $\mathrm{F} 2 \mathrm{a}$, a potent agonist of the vascular thromboxane/endoperoxide receptor, is a platelet thromboxane/endoperoxide receptor antagonist. Prostaglandins 44: 155-163.

6. Malla Z, Philip I, Lebret M, Chatel D, Maclouf J, Tadgui A, 1998 Elevated levels of 8-iso-prostaglandin F2 $\alpha$ in pericardial fluid of patients with heart failure: a potential role for in vivo oxidant stress in ventricular dilatation and progression to heart failure. Circulation 97: 1536-1539.

7. Murai Y, Hishinuma, T, Suzuki N, Satoh J, Toyota T, Mizugaki M, 2000 Determination of 8-epi-prostaglandin F (2alpha) using liquid chromatography-tandem mass spectrometry: increased excretion in diabetics". Prostaglandins Other Lipid Mediat 62: 173-181.

8. Cracowski JL, Cracowski C, Bessard G, et al, 2001 Increased lipid peroxidation in patients with pulmonary hypertension. Am J Crit Care Med 164: 1038-1042.

9. Basu S, Whiteman M, Mattey DL, Halliwell B, 2001 Raised levels of F2-isoprostanes and prostaglandin F2 $\alpha$ in different rheumatic diseases. Ann Rheum Dis 60: 627-631.

10. Handelman GJ, Walter MF, Adhikarla R, et al, 2001 Elevated plasma F2-isoprostanes in patients on long term hemodialysis. Kidney Int 59: 1960-1966.

11. ZouRooz-Zadeh J, 1999 Effect of dialysis on oxidative stress in uremia. Redox Rec 4: 17-32.

12. Massy ZA, Nguyen-Khoa T, 2002 Oxidative stress and chronic renal failure: Markers and management. J Nephrol 15: 336-341.

13. Amberg G, Lindefors N, 1989 Intracerebral microdialysis: II. Mathematical studies of diffusion kinetics. J Pharm Methods 22: 157-183.

14. Simonsen L, Bülow J, Madsen J, 1994 Adipose tissue metabolism in humans determined by vein catheterization and microdialysis techniques. Am J Physiol (Endocrine 
metab. 29) q 266(3Pt1): E 357-365.

15. Maggs DG, Jacob R, Rife F, et al, 1995 Interstitial fluid concentrations of glycerol, glucose and amino acids in human quadriceps and adipose tissue. J Clin Invest 96: 370-377.

16. Langberg H, Skovgaard D, Karamouzis M, Büllow J, Kjaer M, 1999 Metabolism and inflammatory mediators in the peritendinous space measured by microdialysis. $\mathrm{J}$ Physiol 515: 919-927.

17. Karamouzis M, Lanberg H, Kjaer M, Bólow J, Saltin B, 1999 A comparative study of the influence of dynamic and static isometric intermittent contractions on the intramuscular accumulation of prostaglandins and thromboxanes: A study with microdialysis. Medical Biochemistry 1: 233-245.

18. Karamouzis I, Christoulas K, Grekas D, Giannoulis Kl, Vamvakoudis E, Mandroukas K, 2004 The response of muscle interstitial F2-isoprostane (8-iso-PGF2 $\alpha$ ) during dynamic contractions in humans. Prostaglandins Leukotrienes and Essential Fatty Acids 71: 87-90.

19. Walter M, Blumberg J, Dolnikowsi Gr, Handelman G, 2000 Streamlined F2-isoprostane analysis in plasma and urine with HPLC gas chromatography / mass spectroscopy. Analytical Biochemistry 280: 73-79.

20. Ikizler TA, Morrow JD, Roberts LJ, et al, 2002 Plasma F2-isoprostane levels are elevated in chronic hemodialysis patient. Clin Nephrol 58: 190-197.

21. Spittle MA, Holnich NA, Handelman GJ, Adhanarea R, Home P, 2002 Oxidative stress and inflammation in hemodialysis patients. Am J Kidney Dis 38: 1408-14013.

22. Lim PS, Chang YM, Thien LM, et al, 2002 8-iso-prostaglandin F2 $\alpha$ as a useful biomarker of oxidation stress in ESRD patients. Blood Purif 20: 537-542.

23. Ferraro B, Galli F, Frei B, et al, 2003 Peroxynitrite-Induced oxidation plasma lipid is enhanced in stable hemodialysis patients. Kidney Int 63: 2007-2213.

24. Kim K, Jung B, Paeng KJ, Kim SW, Chung BC, 2004 Alteration of plasma total F2-isoprostane before and after hemodialysis in end-stage renal disease patients. Prostaglandins Leukot Essent Fatty Acids 70: 475-478.

25. Hofman SW, Roof RL, Stein DG, 1996 A reliable and sensitive enzyme immunoassay method for measuring 8 -iso-prostaglandin F2 $\alpha$. A marker for lipid peroxidation after experimental brain injury. J Neurosci Methods 68: 133-136.

26. Maxey KM, Maddipati KR, Birkeier J, 1992 Interference in enzyme immunoassay. J Clin Immunoassay 15: 116-
120.

27. Grundmen JU, Wiswedele D, Hirsch D, Gollnick HP, 2004 Detection of monohydroxylicosa retranoic acid and F2-isoprostanel in microdialysis samples of human UV irradiation skin by gas chromatography mass spectrometry. Skin Pharmacol Physiol 17: 37-41.

28. Dietrich M, Block G, Benowitz NL, et al, 2003 Vitamin $\mathrm{C}$ supplementation decreases oxidative stress biomarkers F2-isoprostanes in plasma of nonsmokers exposed to environmental tobacco smoke. Nutr Cancer 45: 176-184.

29. Moreno JJ, Carbonell T, Sanchez T, Miret S, Mitjavila MT, 2001 Olive oil decrease both oxidative stress and production of arachidonic acid metabolites by the prostaglandin $\mathrm{G} / \mathrm{H}$ synthase pathway in rat macrophages. $\mathrm{J}$ Nutr 131: 2145-2149.

30. Wolfam M, Oguogho A, Efthimiou Y, Budinsky G, Sinzinger H, 2002 Effect of black tea on iso-prostaglandins and platelet aggregation in healthy volunteers. Prostaglandis Leukot Essent Fatty Acids 65: 529-533.

31. Kegs A, 1999 Mediterranean diet and public health personal reflection. Am J Clin Nutr 61: 1321-1323.

32. Karamouzis I, Grekas D, Karamouzis M, et al, 2004 The changes of isoprostane 8-iso-PGF2 $\alpha$, in the intracellurar fluids of muscle, hemodialysed patients. Helliniki Iatriki 70: 279-285. (abstract in English)

33. Ward RA, McLeish KR, 1995 Hemodialysis with cellulose membranes primes the neutrophil oxidative burst. Artif Organs 19: 801-807.

34. Canaud B, Cristol J, Morena M, Leray-Moragues H, Bosc J, Vaussenat F, 1999 Imbalance of oxidants and antioxidants in hemodialysis patients. Blood Purif 17: 99-106.

35. Ward RA, McLeish KR, 1995 Polymorphonuclear leukocyte oxidative burst is enhanced in patients with chronic renal insufficiency. J Am Soc Nephrol 5: 1697-1702.

36. Loughrey CM, Young IS, Lightbody JH, McMaster D, McNamee PT, Trimble ER, 1994 Oxidative stress in hemodialysis. Quan J Med 87: 679-683.

37. Morena M, Cristol JP, Bosc JY, et al, 2002 Connective and diffusive losses of vitamin $\mathrm{C}$ during hemodiafiltration session: a contributive factor to oxidative stress in hemodialysis patients. Nephrol Dial Transplant 17: 422-427.

38. Koenig JS, Fischer M, Bulant E, Tiran B, Elmadfa I, Druml W, 1997. Antioxidant status in patients on chronic hemodialysis therapy: impact of parenteral selenium supplementation. Wien Klin Wochenschr 109: 13-19. 